\title{
Perceptions of epilepsy among black students at a University in South Africa
}

\author{
K Peltzer, Ph D, Department of Psychology, University of the North
}

\section{Abstract}

The present study sought to investigate the relationship between familiarity, attitudes, causative and treatment beliefs about epilepsy in a sample of black young adults (university students) in South Africa. The sample included a convenient sample of 253 second year social science students, $98(38.7 \%)$ males and $155(61.3 \%)$ females in the age range from 18 to 42 years $(M=25.0$ years, $(S D=4.2)$. The questionnaire administered to students in a class room situation included sociodemographic data, and sections on familiarity, beliefs about cause and treatment, sources of information, attitudes about epileptics, and prevention of epilepsy. Results showed that the majority of students, in particular from a rural background, were familiar with epilepsy. Health care institutions were the most important source of information on epilepsy, especially for women. Those who believed in traditional causes of epilepsy also endorsed traditional treatment for it, though they did not see such treatment as curative. Those who believed in a medical treatment did however see such treatment as curative. Although the majority of the students had a positive attitude towards epileptics through sharing a meal or room and willingness to marry an epileptic, 17\% thought that epileptics can infect others with their saliva during a seizure, $12 \%$ felt an epileptic is a witch or wizard, and about $10 \%$ said an epileptic must be isolated. Findings should be included in educational programmes for young adults.

\section{Introduction}

A seizure (fit) is the clinical manifestation of abnormal and excessive discharge from nerve cells in the brain. Seizures are classified as provoked (that is, secondary to another disease such as a parasitic infestation or a brain tumor) or as unprovoked idiopathic (that is, without an identifiable precipitating disease or injury). Epilepsy is a disorder of recurrent unprovoked seizures. The prevalence rate in African countries has been three to five times higher than in industrial countries. This is explicable in part by more adverse events in utero, higher likelihood of injury, lack of access to treatment, and parasitic diseases. Desjarlais, Eisenberg, Good \& Kleinman (1995: 169) note that why $90 \%$ of epileptic patients in a number of African societies do not receive biomedical treatment that has proven efficacy is a social question.

Epilepsy is not unique among neurological disorders in having psychosocial consequences, but many myths, misconceptions and prejudices surround epilepsy, and persons with epilepsy face negative societal attitudes and discrimination (McQueen \& Swartz 1995: 859). Epilepsy may be attributed to spirit possession or transgression of ancestral taboos. A person with epilepsy may be shunned and barred from all social intercourse. Marriage may be proscribed for the patient and other family members. Because of the stigma associated with the disease, families often hide afflicted children. In an area of central Ethiopia with an epilepsy prevalence of 5.2 per thousand, a door-to-door survey of 1,500 households revealed that $45 \%$ of those interviewed believed the disorder could be transmitted by physical contact at the time of the attack; three-quarters would not allow a family member to marry a patient with epilepsy and would not employ such a person (Tekle-Haimanot, Abebe, Forsgren et al. 1991: 1363). In many developing countries knowledge about the cause, treatment and cure of epilepsy come from apparently contra- dictory sources. For instance, in different South African societies, the influence of non-medical beliefs is still strong. McQueen, Swartz and Perfile (1995: 209) note about epilepsy and stigma in a South African rural and urban community that attributions of epilepsy to supernatural causes such as witchcraft were reasonably common, as was use of indigenous healing in addition to biomedicine. Among Northern Sotho traditional healers in South Africa it was found that epilepsy belongs to the major conditions treated by traditional healers. From 18 healers who treated epilepsy 12 said the cause was physical or natural and 6 attributed it to supernatural causes (witchcraft and violation of taboo) (Peltzer 1998a: 194). The choice of treatment for epilepsy was seen by 70 adult villagers in South Africa as $71 \%$ traditional or faith healer, $16 \%$ medical and 13\% do not know (Peltzer 1998b: 251). Few indigenous medicine men know how to treat convulsive disorders effectively and except for some herbal remedies, their treatment mostly consists of ritual procedures performed for the patient and the protection of other family members against the dreaded affliction. Epilepsy therefore takes its natural course and the patients may suffer continued uncontrolled seizures (Jilek-Aall \& Jilek 1989: 361f.).

The fact that biomedical medicine can provide effective treatment should not however rule out a role for traditional treatments, if they are beneficial. A step to effective integration is to understand how African people view medical and nonmedical (traditional) ideas about cause and treatment, and how these relate to the belief that epilepsy can be effectively treated (Shaba, MacLachlan, Carr \& Ager 1993: 165).

There are only a few studies investigating the perception of epilepsy among students in tertiary education institutions in industrial countries indicating knowledge deficiencies and stigmatization (Gouvier, Brown \& Prestholdt et al. 1995: 51; Harding, Betts \& Darby 1989: 37; Raeder, Ritter \& Schwibbe 
Table 1: Familiarity with epilepsy by gender and urbanisation level.

\begin{tabular}{|l|l|l|l|l|l|l|}
\hline Variable & $\begin{array}{l}\text { Male } \\
\mathrm{F}(\%)\end{array}$ & $\begin{array}{l}\text { Female } \\
\mathrm{F}(\%)\end{array}$ & $X^{2}$ & $\begin{array}{l}\text { Village } \\
\mathrm{F}(\%)\end{array}$ & $\begin{array}{l}\text { Town } \\
\mathrm{F}(\%)\end{array}$ & $X^{2}$ \\
\hline $\begin{array}{l}\text { Heard/read about } \\
\text { epilepsy }\end{array}$ & $62(63.3)$ & $118(76.1)$ & 7.744 & $112(69.1)$ & $51(56.0)$ & $13.663^{*}$ \\
\hline $\begin{array}{l}\text { Know a person } \\
\text { with epilepsy }\end{array}$ & $52(53.1)$ & $86(55.5)$ & 3.224 & $87(53.7)$ & $41(45.1)$ & $14.073^{*}$ \\
\hline $\begin{array}{l}\text { Seen a person } \\
\text { having seizures }\end{array}$ & $32(32.7)$ & $44(28.4)$ & 1.709 & $52(32.1)$ & $21(23.1)$ & $23.669^{* * *}$ \\
\hline
\end{tabular}

${ }^{* * *} \mathrm{p}<.001 ; * * \mathrm{p}<.01 ;{ }^{*} \mathrm{p}<.05$

1986: 325).

The present study sought, therefore, to investigate the relationship between knowledge, attitudes, causative and treatment beliefs about epilepsy in a sample of black young adults (university students) in South Africa. Specific objectives included: (1) to determine the sources of information about epilepsy and familiarity with epilepsy, (2) to identify the believed causes and treatment modalities of epilepsy, (3) to determine the relationship between causative, treatment and curative beliefs, and (4) to find out socio-demographic differences in regard to familiarity, causative and treatment beliefs of epilepsy. Findings on the perceptions of epilepsy will inform health workers and may improve the management of epilepsy.

\section{Methods}

\section{Sample and procedure}

The sample included a convenient sample of 253 second year social science students from the University of the North, South Africa. The questionnaire was administered to all students in a class room situation and confidentiality was assured.

The students were $98(38.7 \%)$ males and $155(61.3 \%)$ females in the age range from 18 to 42 years $(M=25.0$ years, $(S D=4.2)$. Distribution by ethnicity showed $184(72.7 \%)$ Northern Sotho, 37 (14.6\%) Tsonga, 12 (4.7\%) Venda, and $20(7.9 \%)$ belonging to different ethnic groups. The majority $(162 ; 64 \%)$ come from the village and $91(36 \%)$ grew up or come from town or a township.

\section{Measure}

A questionnaire was developed based on a literature review (e.g., Danesi 1994: 26f., McLin \& de Boer 1995: 958, Nyame \& Biritwum 1997: 140ff., Santos, Guerreiro, Mata et al. 1998: 33, Shaba et al. 1993: 166). Thus, the questionnaire included:

(1) sociodemographic data (age, sex, ethnicity, and socio economic background);

(2) 3 items on familiarity with epilepsy: Have you ever heard or read about the disease called 'epilepsy' or convulsive seizures or epileptic fits? Did you ever know
Table 2: Believed causes of epilepsy by gender in percent

\begin{tabular}{|l|l|l|}
\hline Epilepsy is caused by & Male & Female \\
\hline 1) Brain/central nervous system disorder & 70 & 71 \\
\hline 2) Brain damage & 61 & 64 \\
\hline 3) Mental/emotional disorder & 52 & 70 \\
\hline 4) Inheritance & 51 & 61 \\
\hline 5) Miscellaneous (specific diseases, trauma, etc.) & 50 & 60 \\
\hline 6) Alcohol and drug abuse & 51 & 55 \\
\hline 7) Do not know & 33 & 43 \\
\hline 8) High fever and infection & 30 & 32 \\
\hline 9) Witchcraft. muti or evil spirits & 34 & 22 \\
\hline 10) Accident & 30 & 20 \\
\hline 11) Others, specify & 08 & 09 \\
\hline
\end{tabular}

[Multiple responses included]

anyone who had epilepsy? and Have you ever seen anyone who was having a seizure? (answer: yes or no); Cronbach alpha and split-half reliability coefficient for the 'familiarity' measure were .7 and .6, respectively, for this sample;

(3) 11 items on believed causes of epilepsy (answer: yes or no); an example is "Epilepsy is caused by alcohol and drug abuse"; Cronbach alpha as well as split-half reliability coefficient for the 'causes' measure was 8 for this sample;

(4) 5 items on the treatment of (chronic) epilepsy (answer: yes or no); an example is "herbs"; Cronbach alpha as well as split-half reliability coefficient for the 'treatment' measure was .7 for this sample;

(5) 5 items on beliefs about conceptual causes and treatment: a) traditional cause, b) medical cause, c) traditional treatment, d) medical treatment, and e) curable (rated from $1=$ strongly disagree to $7=$ strongly agree) (see Table 4); Cronbach alpha as well as split-half reliability coefficient for the 'conceptual causes and treatment' measure was .8 for this sample; 
ables were found with regard to urbanrural differences; more students who come from the village have heard or read about epilepsy, know a person with epilepsy, and have seen a person with a seizure than students who come from town.

\section{Causes and treatment}

The believed causes of epilepsy were mainly seen as brain/central nervous disorder and as brain damage. More than half of the participants (52\% males and $70 \%$ females) felt that epilepsy was caused by a mental or emotional disorder, and also more than half saw it as caused by inheritance, specific diseases, trauma, etc., and alcohol and drug abuse. More than a quarter of the university students (males $34 \%$ and fe-

(6) 5 items on sources of information about epilepsy (answer: yes or no) (see Table 5); Cronbach alpha as well as split-half reliability coefficient for the 'information' measure was .5 for this sample;

(7) 17 items on attitudes about epileptics (answer: yes or no); an example is "An epilectic is mentally normal" (see Table 6); Cronbach alpha as well as split-half reliability coefficient for the 'conceptual causes and treatment' measure was .6 for this sample; and

(8) 9 items on prevention of epilepsy; an example is "avoid alcohol" (answer: yes or no) (see Table 7). Cronbach alpha and split-half reliability coefficient for the 'familiarity' measure were .6 and .5 , respectively, for this sample;

\section{Data analysis}

Data were analysed with descriptive, Chi-square, and correlational statistics using SPSS (version 8.0).

\section{Results}

\section{Familiarity with epilepsy}

Table 1 indicates the knowledge and experience with epilepsy by gender and urbanisation level.

The majority of the participants had heard or read about epilepsy $63.3 \%$ males and $76.1 \%$ females), more than half know a person with epilepsy $(53.1 \%$ males and $55.5 \%$ females), and almost a third had seen a person having seizures $(32.7 \%$ males and $28.4 \%$ females). There were no significant gender differences. Significant differences on all vari-

\section{Table 4: Pearson intercorrelations between ratings for causative, treatment, and curative beliefs}

\begin{tabular}{|l|l|l|l|l|l|}
\hline & TC & MC & TT & MT & C \\
\hline Traditional Cause (TC) & 1.000 & & & & \\
\hline Medical Cause (MC) & $.144^{*}$ & 1.000 & & & \\
\hline Traditional Treatment (TT) & $.472^{* * *}$ & .014 & 1.000 & & \\
\hline Medical Treatment (MT) & $.138^{*}$ & $.441^{* * *}$ & .043 & 1.000 & \\
\hline Curable (C) & .108 & $.387^{* * *}$ & .081 & $.357^{* * *}$ & 1.000 \\
\hline
\end{tabular}

*** $\mathrm{p}<001 ;{ }^{* *} \mathrm{p}<01 ;{ }^{*} \mathrm{p}<05$ males $22 \%$ ) believed epilepsy was caused by witchcraft, muti (bad medicine) or evil spirits (see Table 2).

Regarding the treatment of (chronic) epilepsy about $80 \%$ of the participants indicated the doctor and prayers. Women preferred herbs and doing nothing to men (see Table 3 ).

From Table 4 the degree of believing in a traditional cause of epilepsy is associated with the degree of belief in traditional treatment as well as the degree of believing in a medical cause is even stronger associated with the degree of belief in medical treatment. Strength of belief in a cure for epilepsy is not associated with traditional cause nor is traditional treatment. But, there is very significant relationship between strength of belief a medical cause as well as medical treatment and belief in a cure ( $\mathrm{p}<.001$ and $\mathrm{p}<.001$ respectively). Degree of medical orientation to treatment predicts a belief in curative powers, whereas degree of traditional orientation to treatment, by implication, predicts a belief in palliative powers (a preference for traditional treatment but with no expectation of cure) (see Table 4). Gender was not significantly related to any of the variables except for curable with female gender $(p<.007)$.

\section{Sources of information}

Health care institutions are clearly (more than $70 \%$ ) the most 
Table 5: Source of information about epilepsy by frequency and in percent

\begin{tabular}{|l|l|l|l|}
\hline Source of information & $\begin{array}{l}\text { Male } \\
\text { F (\%) }\end{array}$ & $\begin{array}{l}\text { Female } \\
\text { F (\%) }\end{array}$ & $X^{2}$ \\
\hline 1) Health care institutions & $72(73.5)$ & $122(78.7)$ & $8.052^{* *}$ \\
\hline 2) TV and radio & $61(62.2)$ & $67(43.2)$ & $5.057^{*}$ \\
\hline 3) Local and national newspaper & $47(48.0)$ & $47(30.3)$ & $5.155^{*}$ \\
\hline 4) Centres for non/formal education & $43(43.9)$ & $53(34.2)$ & .709 \\
\hline 5) Friends and relatives & $36(36.7)$ & $40(25.8)$ & .1823 \\
\hline
\end{tabular}

[Multiple responses included] ${ }^{* * *} \mathrm{p}<.001 ;{ }^{* *} \mathrm{p}<.01 ; * \mathrm{p}<.05$ nervous disorder and as brain damage, inheritance, and specific diseases, trauma, and alcohol and drug abuse, witchcraft, muti and spirits, etc. For example, Danesi (1994: 26) found among Nigerian university graduates that $61.2 \%$ believed that epilepsy was caused by brain damage, $23.3 \%$ do not know, $13.2 \%$ heredity and $1.5 \%$ witchcraft. Nyame and Biritwum (1997: 140) found in a community sample in Accra, Ghana, that $31.8 \%$ believed heredity, $27.9 \%$ witchcraft, juju and spiritual, $8.1 \%$ brain growth, $7 \%$ accident, $5.9 \%$ alcohol and drug abuse, $4.2 \%$ high fever and infection and $15.1 \%$ other caused responsible for epilepsy. Awaritefe, Longe and Awaritefe (1985: 1) identified in a community sample in Nigeria that the major important source of information on epilepsy, especially for women, followed by TV and radio, newspaper, centers for non/formal education and friends and relatives in that order. Men seem to have significantly more access to newspapers and TV and radio than women (see Table 5).

\section{Attitudes about epileptics}

The majority of the participants have a positive attitude towards epileptics through sharing a meal or room and willingness to marry an epileptic. Most thought epileptics were normal, education should not be denied to them, they should be gainfully employed and also marry.

Almost half of the participants (45\%) felt that an epileptic should be held responsible for actions during fit, $17 \%$ thought that epileptics can infect others with their saliva during a seizure, $12 \%$ felt an epileptic is a witch or wizard, and about $10 \%$ said an epileptic must be isolated (see Table 6). perceived causes of epilepsy reported were heredity, witchcraft, and brain damage, in that order, not infection. More than half of the participants felt that epilepsy was caused by a mental or emotional disorder. Contrary to popular myth, intelligence is not impaired by epilepsy per se. However, childhood epilepsy is associated with a fourfold increase in risk for psychiatric disorder (Desjarlais et al. 1995: 167).

It is noteworthy that $84 \%$ of the participants would go to a doctor for the treatment of epilepsy but also more than $80 \%$ would pray and $50 \%$ use herbs. It appears that prayers are invariable in most treatment regimes in the South African context, whatever the illness.

The finding that a belief in a traditional cause is strongly associated with a belief in traditional treatment, but that neither of these beliefs (in traditional cause or treatment) are associated with a belief that epilepsy is curable concurs with a community population in Malawi (Shaba et al. 1993: 167).
Prevention of epilepsy

Participants rated as major reasons for prevention of epilepsy avoiding alcohol, prayers, balanced diet, avoiding an accident, and delivery in hospital in order of descending importance (see Table 7).

\section{Discussion}

The majority of the students were familiar with epilepsy (heard about it or know someone with epilepsy), which concurs with other studies (e.g. in a community sample in Brasil, Santos et al. 1998: 35). The finding that familiarity with epilepsy was significantly higher in the students from a rural background is interesting and needs further investigation.

The believed causes of epilepsy were similar to that found in other studies, such as brain/central

\section{Table 7: Prevention of epilepsy}

\begin{tabular}{|l|l|l|}
\hline How to prevent epilepsy & Male F (\%) & Female F (\%) \\
\hline 1) Avoid alcohol & $75(76.5)$ & $115(74.2)$ \\
\hline 2) Prayers & $71(72.4)$ & $96(61.9)$ \\
\hline 3) Balanced diet & $65(66.3)$ & $96(61.9)$ \\
\hline 4) Avoid accident & $65(66.3)$ & $70(45.8)$ \\
\hline 5) Delivery in hospital & $56(57.1)$ & $80(51.6)$ \\
\hline 6) Not marry into epileptic family & $25(25.5)$ & $26(16.8)$ \\
\hline 7) Can't be prevented & $22(22.4)$ & $25(16.1)$ \\
\hline 8) Not touching a patient fitting & $12(12.2)$ & $18(11.6)$ \\
\hline $\begin{array}{l}\text { 9) Others (relaxation, avoid stress, use of herbs, } \\
\text { stick to prescribed medication, consult specialist, etc.) }\end{array}$ & $18(18.4)$ & $25(16.1)$ \\
\hline
\end{tabular}

[Multiple responses included] 
Table 6: Attitudes about epileptics by frequency and percent

\begin{tabular}{|l|c|l|}
\hline Statements & F & $\%$ \\
\hline 1) An epileptic is mentally normal & 142 & 56.6 \\
\hline 2) Epilepsy can spread by contact & 31 & 12.5 \\
\hline $\begin{array}{l}\text { 3) People with epilepsy can infect others with } \\
\text { their saliva during a seizure }\end{array}$ & 45 & 16.9 \\
\hline $\begin{array}{l}\text { 4) If a fellow student has a seizure in university } \\
\text { you will avoid contact with him or her }\end{array}$ & 27 & 10.6 \\
\hline 5) An epileptic is a witch/wizard & 30 & 12.1 \\
\hline 6) Epileptic is a disability & 65 & 25.5 \\
\hline 7) Epileptic must be isolated & 25 & 9.6 \\
\hline 8) Epileptic patient should be avoided & 18 & 7.2 \\
\hline $\begin{array}{l}\text { 9) Epileptic should be held responsible fro actions } \\
\text { during fit }\end{array}$ & 113 & 45.2 \\
\hline 10) Epileptic should not be educated & 39 & 15.2 \\
\hline 11) An epileptic should marry & 195 & 78.0 \\
\hline 12) An epileptic should drive & 51 & 20.1 \\
\hline 13) An epileptic should be gainfully employed & 185 & 73.3 \\
\hline 14) Willingness to eat with an epileptic & 195 & 77.3 \\
\hline 15) Willingness to share a room with an epileptic & 202 & 80.0 \\
\hline 16) Willingness to marry an epileptic & 174 & 68.8 \\
\hline $\begin{array}{l}\text { 17) Students with epilepsy should be separate from } \\
\text { other students in the class }\end{array}$ & 33 & 12.9 \\
\hline
\end{tabular}

[Multiple responses included]

A weak correlation between a belief in either a medical or traditional cause of epilepsy indicates that those who believe in a medical cause may or may not also believe in a traditional cause. Thus, some participants may see epilepsy as having a dual cause both medical and traditional. This is further supported by a weak correlation between traditional cause and medical treatment.

Health care institutions are clearly the most important source of information on epilepsy, especially for women, followed by TV and radio. This finding may be included in health education about epilepsy.

The finding that the majority of the participants had a positive attitude towards epileptics through sharing a meal or room and willingness to marry an epileptic concurred with other studies (e.g. Danesi 1994: 26, Nyame and Biritwum 1997:
141). In this sample, however, higher rates of negative attitudes towards epileptics was found in regard to the following questions: (1) epileptics can infect others with their saliva during a seizure (16.9\%), (2) epileptic should be held responsible for actions during fit $(45.2 \%)$, (3) students with epilepsy should be separate from other students in class (12.9\%), and (4) an epileptic is a witch/wizard (12.1\%) (e.g. Nyame and Biritwum 1997: 141). People believe that the saliva or other excretions are contagious, especially during an attack, and that touching the convulsing person may cause the epilepsy spirit to leap over onto one (Jilek-Aall, Jilek. Kaaya et al. 1997: 784). With respect to attitudes towards epileptics this sample needs further health education.

Preventive measures inquired about are for some items similar to that of a community study in urban Ghana: prayer (29.1\%), delivery of babies in hospitals (21.6\%) and to avoid marrying into epileptic families (15.4\%). However, in some items this sample had much higher rates, e.g. avoid alcohol $(75 \%)$, balanced diet $(63 \%)$, and avoid accident (55\%) (Nyame \& Biritwum 1997: 142).

\section{Conclusion and recommendation}

The majority of the students were familiar with epilepsy (heard about it or know someone with epilepsy). Although the majority of the participants had a positive attitude towards epileptics through sharing a meal or room and willingness to marry an epileptic. However, there were some areas of concern such as that more than a quarter of the university students believed epilepsy was caused by witchcraft, muti or evil spirits, almost half (45\%) felt that an epileptic should be held responsible for actions during fit, $17 \%$ thought that epileptics can infect others with their saliva during a seizure, $12 \%$ felt an epileptic is a witch or wizard, and about $10 \%$ said an epileptic must be isolated. These areas need health education considering the different sources of information about epilepsy.

The perceptions of black South African University students suggest that there is a differentiation between the effects of medical and traditional treatment for epilepsy. Since a traditional cause was also associated with a medical cause and medical but not traditional treatment, it may be that the two approaches (traditional as palliative and medical as curative) could be blended into one approach (Shaba et al. 1993: 167). The ability of students to simultaneously hold medical and traditional beliefs about epilepsy is noted (Shaba et al. 1993: 165). Data should help in addressing health promotion by designing educational programmes among young adults 


\section{References}

AWARITEFE A; LONGE AC \& AWARITEFE M 1985 : Epilepsy and psychosis: a comparison of societal attitudes. Epilepsia 26: 1-9.

DANESI MA 1994 : VII Epilepsy and the secondary schools in Nigeria. Tropical and Geographical Medicine (Supplement) 46: $25-27$

DESJARLAIS R; EISENBERG L; GOOD B \& KLEINMAN A 1995 : World mental health: problems and priorities in low-income countries. New York: Oxford University Press.

HARDING G; BETTS T \& DARBY P 1989 : Epilepsy in tertiary education. Educational and Child Psvchology 6: 37 43.

GOUVIER WD; BROWN LM; PRESTHOLDT PH; HAYES JS ET AL 1995 : A survey of common misconceptions about epilepsy. Rehabilitation Psychology 40: 51-59.

JILEK-AALL L \& JILEK WG 1989 : Epilepsy and its psychosocial implications in Africa. In: K. Peltzer \& P.O. Ebigbo (eds.) Clinical psychologv in Africa (pp. 353-364). Frankfurt/M.: IKO Verlag.

JILEK-AALL L; JILEK M; KAAYA, J; MKOMBACHEPA L \& HILLARY K 1997 : Psychosocial study of epilepsy in Africa. Social Science \& Medicine 45: 783-795.

MCLIN WM; DE BOER HM 1995 : Public perceptions about epilepsy. Epilepsia 36: 957-959.

MCQUEEN AH \& SWARTZ L 1995 : Reports of the experience of epilepsy in a rural South African village. Social Science \& Medicine 40: 859-865.

MCQUEEN AH; SWARTZ L \& PERFILE LL 1995 : Epilepsy and psychosocial adjustment: a selective review. South African Journal of Psychology 25: 207-210.

NYAME PK \& BIRITWUM RB 1997 : Epilepsy: knowledge, attitude and practice in a literate urban population, Accra, Ghana. West African Journal of Medicine 16: 139145.

PELTZER K 1998a : A community survey of traditional healers in South Africa (Northern Province). South African Journal of Ethnology 21: 191-198.

PELTZER K 1998b : Traditional healing for mental and social disorders in the Northern Province (South Africa). In: L. Schlebusch (ed.) South Africa beyond transition: psychological well-being (pp. 248-251). Pretoria: The Psychological Society of South Africa.

RAEDER K; RITTER G \& SCHWIBBE MH 1986 : Epilepsy and prejudice: the dimensionality of stereotypes towards epileptics. International Journal of Rehabilitation

Research 9: 325-334.
SANTOS IC; GUERREIRO MM; MATA A ET AL 1998 : Public awareness and attitudes toward epilepsy in different social segments in Brazil. Arg Neuropsiquiatr 56: 32-38.

SHABA R; MACLACHLAN M; CARR SC \& AGER A 1993 : Palliative versus curative beliefs regarding tropical epilepsy as a function of traditional and medical attributions. Central African Journal of Medicine 39: 165-167.

TEKLE-HAIMANOT R; ABEBE M; FORSGREN L ET AL 1991 : Attitudes or rural people in Central Ethiopia toward epilepsy. Social Science \& Medicine 32: 203-209. 